Article

\title{
Dietary, Nutrient Patterns and Blood Essential Elements in Chinese Children with ADHD
}

\author{
Fankun Zhou ${ }^{1,2}$, Fengyun $\mathrm{Wu}^{2}$, Shipu Zou ${ }^{3}$, Ying Chen ${ }^{2}$, Chang Feng ${ }^{2}$ and Guangqin Fan ${ }^{1,2, *}$ \\ 1 State Key Laboratory of Food Science and Technology, Nanchang University, Nanchang 330047, China; \\ zhoufankun66@163.com \\ 2 Department of Occupational Health and Toxicology, School of Public Health, Nanchang University, \\ Nanchang 330006, China; waterncu@126.com (F.W.); goldncu@163.com (Y.C.); gloriqina@163.com (C.F.) \\ 3 Department of Child Healthcare, Children's Hospital of Jiangxi Province, Nanchang 330006, China; \\ zoushipujxch@126.com \\ * Correspondence: fanguangqin@ncu.edu.cn; Tel.: +86-791-8636-2283; Fax: +86-791-8636-0579
}

Received: 23 April 2016; Accepted: 1 June 2016; Published: 8 June 2016

\begin{abstract}
Dietary or nutrient patterns represent the combined effects of foods or nutrients, and elucidate efficaciously the impact of diet on diseases. Because the pharmacotherapy on attention deficit hyperactivity disorder (ADHD) was reported be associated with certain side effects, and the etiology of ADHD is multifactorial, this study investigated the association of dietary and nutrient patterns with the risk of ADHD. We conducted a case-control study with 592 Chinese children including ADHD $(n=296)$ and non-ADHD $(n=296)$ aged 6-14 years old, matched by age and sex. Dietary and nutrient patterns were identified using factor analysis and a food frequency questionnaire. Blood essential elements levels were measured using atomic absorption spectrometry. A fish-white meat dietary pattern rich in shellfish, deep water fish, white meat, freshwater fish, organ meat and fungi and algae was inversely associated with ADHD $(p=0.006)$. Further analysis found that a mineral-protein nutrient pattern rich in zinc, protein, phosphorus, selenium, calcium and riboflavin was inversely associated with ADHD $(p=0.014)$. Additionally, the blood zinc was also negatively related to $\operatorname{ADHD}(p=0.003)$. In conclusion, the fish-white meat dietary pattern and mineral-protein nutrient pattern may have beneficial effects on ADHD in Chinese children, and blood zinc may be helpful in distinguishing ADHD in Chinese children.
\end{abstract}

Keywords: ADHD; dietary pattern; nutrient pattern; blood essential elements; Chinese children

\section{Introduction}

Attention deficit hyperactivity disorder (ADHD), one of the most common childhood psychiatric disorders, is a worldwide public problem that is characterized by developmentally inappropriate levels of inattention, impulsivity, and hyperactivity [1,2]. This disorder in children can severely affect their school performance, family relationships, and social interactions [3]. Currently, the treatment of ADHD is mainly dependent on the pharmacotherapy that involves stimulant medications, such as methylphenidate, amphetamine, and atomoxetine, which has shown a high effectiveness in ADHD treatment [4-7], but it has been reported by several studies to be associated with certain side effects [6-8]. The etiology of ADHD is multifactorial, and diet is an influencing factor of ADHD that is amenable to modification [9].

Based on current studies, diets that reduce the symptoms associated with ADHD include restricting or eliminating the detrimental dietary factors that are associated with the risk of ADHD and supplementing the beneficial dietary factors that protect against ADHD [10-16]. For the detrimental dietary factors, the proposed dietary treatments include restricting sugar and ensuring additive/preservative-free foods (Feingold Diet) and an oligoantigenic diet (elimination) [11-13]. 
However, restricting or eliminating the detrimental dietary factors is complicated, time-consuming, disruptive to the household, and often impractical, except for selected patients. For the beneficial dietary factors, the proposed dietary treatments include polyunsaturated fatty acids (PUFAs) or omega-3 supplements, minerals such as iron and zinc supplements, as well as a megavitamin supplement diet. Supplemental diet therapy is simple, relatively inexpensive, and more acceptable to the patients and parents [10,14-16].

Foods and nutrients are consumed in various characteristic combinations that synergistically influence the risks related to many diseases. Dietary or nutrient patterns represent a broader series of food and nutrient consumption that is more predictive of disease risk than individual foods or nutrients [17]. In recent years, researchers have transferred their focus from individual food or nutrition factors to dietary patterns. Some studies suggested that a healthy diet pattern and lifestyle to prevent or control ADHD might have greater long-term success [10,18-20]. Isolated studies have reported on the relationships between dietary patterns and ADHD [18-20]. Howard et al. and Azadbakht et al. have examined unhealthy dietary patterns associated with ADHD in their cross-sectional studies $[18,19]$. In the adolescents of Western Australia, Howard et al. reported that a Western-style dietary pattern consisting of a high intake of fat, refined sugars, and sodium and a low intake of fiber, folate, and omega-3 fatty acids was associated with increased odds of an ADHD diagnosis, whereas a healthy dietary pattern, with a high intake of fiber, folate, and omega-3 fatty acids, was not correlated with the diagnosis of ADHD [18]. In Iranian school-aged children, dietary patterns characterized by a high intake of sweets and fast food were associated with a greater risk of ADHD; however, no significant association was observed for the healthy or Western dietary patterns [19]. The above cross-sectional investigations indicated the association between dietary patterns and ADHD. A recent further analytical study conducted in Korean school-aged children by Woo et al. studied the likely causal relationship between dietary patterns and ADHD using factor analysis and $24 \mathrm{~h}$ diet recall (24HR) interview based on a case-control study [20]. The results showed that a traditional, healthy dietary pattern that was characterized by a high intake of kimchi, grains, and bonefish and a low intake of fast foods and beverage, was inversely associated with ADHD [20]. However, the traditional foods or eating habits were different in different regions, and a food frequency questionnaire is more suitable for researching the relationship between diet intake and chronic diseases, including ADHD [21]. Thus, the association between the dietary patterns and ADHD, especially nutrient patterns that have been not researched in the previous studies, should be further explored to provide a scientific basis for preventing or controlling ADHD. In the current research, a matched case-control study was conducted to investigate the dietary patterns and nutrient patterns using factor analysis and a food frequency questionnaire among Chinese school-aged children with ADHD. In addition, an association between the blood essential elements (iron, zinc, calcium, copper and magnesium) and ADHD was evaluated in Chinese children.

\section{Methods and Materials}

\subsection{Study Population and Recruitment}

The matched case-control study participants were consecutively recruited from children attending pediatric clinics for health care and ADHD assessment from the Jiangxi Provincial Children's Hospital in Jiangxi Province, China. This hospital, which is the largest hospital that specifically treats children in Jiangxi province, serves children from all of the administrative districts within the province.

The subjects with ADHD 10th revision of the International Statistical Classification of Diseases and Related Health Problems (ICD-10 codes F90, 208-210) were children of Chinese Han nationality who were aged 6-14 years at the time of the investigation and had a lifetime medical history that fulfilled the Diagnostic and Statistical Manual of Mental Disorders, 4th ed., revised Diagnostic and Statistical Manual of Mental Disorders, 4th ed. (DSM-IV-R) criteria for ADHD [1]. The individuals were excluded for any evidence of identifiable prenatal insults, autism, Asperger syndrome, epilepsy 
or a primary diagnosis of schizophrenia, affective disorder, pervasive developmental disorder (ICD-10 codes F84.0-F84.9, 308.0), and mental retardation (ICD-10 codes F70-F79, 312-315).

The non-ADHD control children were randomly selected from those receiving routine health care at the same clinics where the ADHD cases were diagnosed. The controls were given the same full diagnostic assessment as the ADHD cases and screened only for the absence of ADHD without exclusion of any other diagnosis except for the same exclusion criteria applied to ADHD cases. By the pair-matched design, each subject with ADHD and control set had the same sex and the same age (difference between birthdays was within six months).

The face-to-face interviews were performed in the outpatient clinic by graduate students in epidemiology, and the ADHD diagnosis was made by experienced board-certified child psychiatrists. The design and conduct of the survey was performed according to the guidelines laid down in the Declaration of Helsinki, and all of the procedures involving human subjects/patients were approved by the Institutional Review Board of the First Affiliated Hospital of Nanchang University. Informed consent was obtained from the parents of all of the children before participation.

\subsection{Data Collection}

The parents of the participating subjects with ADHD and controls were interviewed in person by the study personnel. All of the personnel were current graduate students in epidemiology. Each interviewer was trained in epidemiologic interviewing, dietary assessment, and anthropometry. All of the interviews with the parents of subjects with ADHD and controls were conducted by two individuals under similar conditions. The data were collected using a standardized and structured questionnaire by individuals who were blinded to the subject or control status of the participants. The data collected included demographic information and other relevant factors related to their children, including the family structure, home environment, socioeconomic status, maternal and paternal education, maternal age at childbirth, smoking behavior of the parents, and medical, obstetric, neuro-developmental, and educational histories of the children, as well as the dietary habits in the 12 months before diagnosis (ADHD-patient) or interview (control subjects). The body mass index (BMI) was calculated $\left(\mathrm{kg} / \mathrm{m}^{2}\right.$ ) based on weight and height measurements with the subjects wearing light clothes and no shoes, according to standard protocols by the World Health Organization (WHO) [22].

\subsection{Dietary Assessment and Food Grouping}

Dietary intake was assessed by a food frequency questionnaire (FFQ), which consisted of 144 food items that were commonly consumed by the Chinese children. All of the questionnaires used for data collection were designed by a panel of experts, including scientists in the fields of epidemiology and nutrition. For each food item, the parents were invited to indicate their children's average frequency of consumption over the past year in terms of the specified serving size by checking one of nine frequency categories, which ranged from "almost never" to " $\geqslant 6$ times/day" [23]. Photographs of the food portion sizes were provided to help estimate the amount of food consumption. The selected frequency category for each food item was converted to a value in number of servings per day. Portion sizes of consumed foods were converted to grams ( $\mathrm{g}$ ) by using household measurements. To reduce the complexity of the data, we categorized the 144 items into 28 food groups based on the similarities between the nutrient profiles or processing methods, as shown in Table A1, regarding dietary pattern analyses. The average daily intake of nutrients and total energy were calculated according to the Chinese Standard Food Composition Table [24,25]. The questionnaires were excluded from additional analyses if energy intake was implausible ( $<700 \mathrm{kcal} /$ day or $>6000 \mathrm{kcal} / \mathrm{day})$, corresponding to the percentiles $<2.5 \%$ or $>97.5 \%$, respectively.

The reliability of the FFQ in this study was evaluated in a randomly chosen subgroup of 62 children by comparing nutrient consumption determined by responses on the FFQ on two occasions. The FFQ had a high reliability for nutrients. Mean value for intake of total energy and most nutrients assessed by the FFQ on two occasions were not statistically different. Energy-adjusted correlation coefficients 
for the principal macronutrients ranged from 0.38 for proteins to 0.65 for zinc. Comparative validity was determined by comparison with intakes estimated from the average of six non-consecutive $24 \mathrm{~h}$ dietary recalls. We found that most nutrients were moderately correlated (all correlation coefficients $>0.4$ ) between these two methods after controlling for total energy intake. Overall, these data indicated that the FFQ provides reasonably valid measurements of average long-term dietary intake.

\subsection{Blood Sampling and Analysis}

Venous whole blood samples $(2 \mathrm{~mL} /$ child) were collected from the cubital vein using a metal-free and heparinized vacuum tube. The concentrations of blood iron, zinc, calcium, copper and magnesium were measured using atomic absorption spectrometry (BH5100, Beijing Optoelectronic Technology Co., Ltd., Bo Hui innovation, Beijing, China). The detection limits for iron, zinc, calcium, copper and magnesium were $6.0 \mu \mathrm{g} / \mathrm{L}, 1.0 \mu \mathrm{g} / \mathrm{L}, 3.0 \mu \mathrm{g} / \mathrm{L}, 1.0 \mu \mathrm{g} / \mathrm{L}$ and $0.1 \mu \mathrm{g} / \mathrm{L}$, respectively. The values were the means of four analyses of each sample. The quality control measures showed the inter-run coefficients of variation of $3.0 \%-5.0 \%$ for these elements.

\subsection{Covariates}

Sex and age are associated with the prevalence of ADHD, which was demonstrated in several epidemiologic studies [26,27]. To address these important confounding factors, we employed a pair-match design on age and sex; thus, the stratified control subjects were at risk at the same sex and age.

Additionally, we considered multiple covariates and potential confounders for the association of dietary patterns, nutrient patterns, blood elements and ADHD in our study. They were based on the established predictors of child behavioral problems $[26,28,29]$. The following variables were used: perinatal distress (low birth weight and admission to a neonatal intensive care unit as markers), household composition (normal: child lives with biological parents; single: child lives with only one parent; or recombined: child lives in remarried family), family history of ADHD (ADHD in parents and siblings, diagnosed by psychiatrists, obtained from clinical reports), maternal smoking during pregnancy (at least one cigarette per day during the last trimester), maternal drinking during pregnancy (at least two glasses per week during the entire pregnancy), paternal smoking at the time of childbirth, labor complications, maternal abortion history, maternal age at childbirth, parents' education, household income, breast feeding, emotional abuse, and family conflicts. These variables were obtained from the clinical records or questionnaires completed by direct interviews with the parents.

\subsection{Statistical Analysis}

We used paired $t$-tests (continuous variables) or paired $\chi^{2}$ tests (categorical variables) to compare the demographic characteristics and other ADHD risk factors between the subjects with ADHD and controls. Factor analysis was adopted to derive the major dietary patterns on the basis of the 28 food groups [30]. To identify the number of factors to be retained, we used the criterion of eigenvalues $>1.0$, scree test, and interpretability [31]. Finally, four major dietary patterns were identified. Those factors were rotated by orthogonal transformation (VARIMAX procedure) to achieve a simpler structure with greater interpretability. Factor loadings represent correlation coefficients between individual food groups and dietary patterns, and those food groups having high absolute loadings $(\geqslant 0.3)$ were considered to be the primary contributors [32]. The proportion of variance explained by each factor was calculated by dividing the sum of the squares of the respective factor loadings by the number of variables. The factor scores for each pattern and for each individual were determined by summing the intakes of each food group weighted by the factor loading [31]. The scores were used for comparison with dietary intake and were divided into tertiles (T1-T3) according to the distribution of factor scores among the controls to estimate their associations with ADHD. Energy-adjusted means for dietary variables across quintiles of dietary pattern scores were calculated. Energy adjustment by using 
the residual method was performed after entering the food groups in the factor analysis and after analyzing the dietary pattern [33]. The same methods were used to analyze the nutrient patterns, and four major nutrient patterns were identified.

The conditional logistic regressions were used to evaluate the association between the dietary and nutrient patterns and ADHD. For each pattern, T1 was considered to be the reference. The univariate and multivariate analyses were applied to calculate the odds ratios (ORs) and their corresponding 95\% confidence intervals (CIs). In the univariate analyses, the crude ORs were calculated without any adjustment in the first model. In the multivariate analyses, we made adjustments for the other potential confounding factors (including BMI, energy intake, family history of ADHD, household composition, maternal smoking during pregnancy, maternal drinking during pregnancy, paternal smoking before childbirth, paternal smoking after childbirth, maternal abortion history, maternal age at childbirth, parents' education, household income, labor or delivery complications, birth weight, twin, full-term pregnancy, breast feeding, emotional abuse, and family conflicts). All of the covariates were introduced using the forward stepwise method. To test for linear trends, the dietary pattern groups for each factor were treated as continuous variables. We also performed a conditional logistic regression analysis with a binary outcome of ADHD in relation to the blood element levels. In addition, the ORs and 95\% CIs of ADHD for each blood element were then calculated as the risk for a change in the blood element level by one standard deviation (SD). Meanwhile, adjustments for other potential confounding factors were made.

SPSS software (version 17.0, Chicago, IL, USA) was used for all of the statistical analyses, and $p<0.05$ was considered to be statistically significant.

\section{Results}

Of the 340 children with ADHD diagnosed in pediatric clinics, $11(3.2 \%)$ did not meet the selection criteria for this study. Of the 329 eligible subjects, 33 (10.0\%) were excluded because of refusal to participate or unreasonable energy intakes (reasonable range, 700-6000 kcal/day). Finally, a total of 296 ADHD subjects were retained in this analysis, including 248 boys and 48 girls. Additionally, 296 eligible age- $( \pm 6$ months) and gender-matched controls were recruited from the same pediatric clinics.

The demographics and other characteristics are shown in Table 1. Compared with the controls, the subjects with ADHD were more likely to suffer from emotional abuse, have low maternal education and maternal abortion history along with a higher likelihood of a family history of ADHD, and were unlikely to have a household with two biological parents or full-term pregnancy. The subjects with ADHD and controls did not differ in BMI, breast feeding, birth weight, labor or delivery complications, twin, household income, maternal age at childbirth, paternal education, family conflicts, maternal drinking during pregnancy, maternal smoking during pregnancy, paternal smoking before childbirth, and paternal smoking after childbirth and energy intake.

Table 1. Demographic and distribution of the risk factors of ADHD and controls ${ }^{1}$.

\begin{tabular}{cccc}
\hline Characteristic & ADHD $(\boldsymbol{n = 2 9 6 )}$ & Controls $(\boldsymbol{n = 2 9 6 )}$ & $\boldsymbol{p}^{\mathbf{2}}$ \\
\hline & Matched Factors & & - \\
\hline Age (years) & $8.42 \pm 1.72$ & $8.46 \pm 1.84$ & - \\
\hline Male & Gender & & \\
\hline Female & $248(83.8)$ & $248(83.8)$ & $48(16.2)$ \\
\hline
\end{tabular}


Table 1. Cont.

\begin{tabular}{|c|c|c|c|}
\hline Characteristic & $\operatorname{ADHD}(n=296)$ & Controls $(n=296)$ & $p^{2}$ \\
\hline \multicolumn{4}{|c|}{ Child Factors } \\
\hline BMI $\left(\mathrm{kg} / \mathrm{m}^{2}\right)$ & $16.00 \pm 3.00$ & $16.41 \pm 2.93$ & 0.263 \\
\hline Energy intake (kcal/day) & $1778.4 \pm 508.1$ & $1895.7 \pm 631.9$ & 0.681 \\
\hline Breast feeding & $172(58.1)$ & $182(61.5)$ & 0.225 \\
\hline Emotional abuse & $180(60.8)$ & $101(34.1)$ & $<0.001$ \\
\hline Birth weight (kg) & $3.27 \pm 0.56$ & $3.24 \pm 0.52$ & 0.436 \\
\hline Full-term pregnancy & $254(85.8)$ & $273(92.2)$ & 0.017 \\
\hline Labor or delivery complications & $29(9.8)$ & $21(7.1)$ & 0.150 \\
\hline Twin & $16(5.4)$ & $14(4.7)$ & 0.426 \\
\hline Family history of ADHD & $40(13.5)$ & $21(7.1)$ & 0.007 \\
\hline \multicolumn{4}{|c|}{ Family Environmental Factors } \\
\hline \multicolumn{3}{|c|}{ Household composition } & \multirow{4}{*}{0.011} \\
\hline Two parents & $210(70.9)$ & $241(81.4)$ & \\
\hline Single parent & $20(6.8)$ & $17(5.7)$ & \\
\hline Recombined & $66(22.3)$ & $38(12.9)$ & \\
\hline \multicolumn{3}{|c|}{ Household income (yuan/month/person) } & \multirow{4}{*}{0.922} \\
\hline$\leqslant 1000$ & $95(32.1)$ & $93(30.7)$ & \\
\hline $1000-2000$ & $99(33.4)$ & $99(33.4)$ & \\
\hline$\geqslant 2000$ & $102(34.5)$ & $106(35.8)$ & \\
\hline Maternal age at childbirth & $25.39 \pm 3.46$ & $25.55 \pm 3.60$ & 0.609 \\
\hline \multicolumn{3}{|c|}{ Maternal education (years) } & \multirow{4}{*}{0.032} \\
\hline$\leqslant 9$ & $37(12.5)$ & $55(18.6)$ & \\
\hline $9-12$ & $126(42.6)$ & $101(34.1)$ & \\
\hline$\geqslant 12$ & $133(44.9)$ & $140(47.3)$ & \\
\hline \multicolumn{3}{|c|}{ Paternal education (years) } & \multirow{4}{*}{0.229} \\
\hline$\leqslant 9$ & $22(7.4)$ & $28(9.5)$ & \\
\hline $9-12$ & $116(39.2)$ & $102(34.5)$ & \\
\hline$\geqslant 12$ & $158(53.4)$ & $166(56.0)$ & \\
\hline Maternal abortion history & $107(36.1)$ & $76(25.7)$ & 0.004 \\
\hline Family conflicts & $11(3.7)$ & $10(3.4)$ & 0.500 \\
\hline Maternal drinking during pregnancy & $3(1.0)$ & $3(1.0)$ & 0.657 \\
\hline Maternal smoking during pregnancy & $2(0.7)$ & $1(0.3)$ & 0.500 \\
\hline Paternal smoking before childbirth & $151(51.0)$ & $141(47.6)$ & 0.230 \\
\hline Paternal smoking after childbirth & $372(40.2)$ & $101(34.1)$ & 0.074 \\
\hline
\end{tabular}

For dietary pattern analysis, four primary factors were retained from the factor analysis. The factor loadings associated with each pattern are shown in Table 2 . The high positive loadings indicate strong associations between given food groups and patterns, whereas the negative loadings indicate negative associations with the patterns. Each pattern was labeled according to the food groups with high absolute loadings $(\geqslant 0.3)$. Factor 1 , with high loadings for leafy vegetables, fruiting vegetables, tuber vegetables, fruits, and root vegetables was labeled as the "vegetable-fruit" dietary pattern. Factor 2, with high loadings for shellfish, deep water fish, white meat, freshwater fish, organ meat, and fungi and algae was labeled as the "fish-white meat" dietary pattern. Factor 3, with high loadings for process grains, soya beans, grains, and other beans, but low loadings for drinks was labeled as the "grain-bean" dietary pattern. Factor 4, with high loadings for fast food, ice cream, sweets, snacks, and red meat, but low loadings for dairy products was labeled as the "fast food-sweet" dietary pattern. Overall, the four dietary patterns accounted for $32.50 \%$ of the variance in food intake. The univariate 
conditional logistic regression analyses showed a dose-dependent inverse association between the risk of ADHD and the fish-white meat dietary pattern ( $p$ trend $=0.003$ ) and grain-bean dietary pattern ( $p$ trend $=0.018$ ) (Table 3$)$. With adjustments made in model 2 for other potential confounding factors, significant negative relationships were observed between the risk of ADHD and the fish-white meat dietary pattern (T3 vs. T1: OR, 0.44; 95\% CI, 0.27-0.73; $p$ trend $=0.006$ ). No association with ADHD was observed for any other dietary pattern (Table 3$)$.

Table 2. Factor loading matrix for the four identified dietary patterns in the study children ${ }^{1}$.

\begin{tabular}{|c|c|c|c|c|}
\hline \multirow{2}{*}{ Food Groups or Foods ${ }^{2}$} & \multicolumn{4}{|c|}{ Dietary Patterns } \\
\hline & $\begin{array}{c}\text { Factor 1 } \\
\text { (Vegetable-Fruit) }\end{array}$ & $\begin{array}{c}\text { Factor } 2 \\
\text { (Fish-White Meat) }\end{array}$ & $\begin{array}{c}\text { Factor } 3 \\
\text { (Grain-Bean) }\end{array}$ & $\begin{array}{c}\text { Factor } 4 \\
\text { (Fast Food-Sweet) }\end{array}$ \\
\hline Leafy vegetables & 0.71 & 0.01 & 0.11 & 0.02 \\
\hline Fruiting vegetables & 0.68 & 0.03 & 0.24 & 0.01 \\
\hline Tuber vegetables & 0.67 & 0.07 & 0.10 & -0.01 \\
\hline Fruits & 0.47 & 0.21 & -0.12 & -0.02 \\
\hline Root vegetables & 0.35 & 0.00 & 0.25 & -0.05 \\
\hline Shellfish & -0.13 & 0.65 & 0.10 & -0.05 \\
\hline Deep water fish & -0.12 & 0.58 & 0.11 & -0.10 \\
\hline White meat & 0.04 & 0.54 & -0.05 & 0.02 \\
\hline Freshwater fish & 0.08 & 0.51 & 0.02 & -0.15 \\
\hline Organ meat & 0.00 & 0.50 & -0.06 & 0.05 \\
\hline Fungi and algae & 0.21 & 0.42 & 0.10 & -0.02 \\
\hline Condiments & 0.12 & 0.24 & -0.07 & 0.13 \\
\hline Animal fats & -0.01 & -0.24 & -0.11 & 0.02 \\
\hline Nuts & 0.14 & 0.14 & 0.05 & -0.02 \\
\hline Process grains & -0.14 & -0.22 & 0.69 & 0.21 \\
\hline Soya beans & 0.10 & 0.03 & 0.62 & 0.01 \\
\hline Grains & -0.14 & -0.12 & 0.57 & -0.15 \\
\hline Drinks & -0.07 & 0.06 & -0.53 & 0.22 \\
\hline Other beans & 0.22 & 0.10 & 0.41 & 0.04 \\
\hline Vegetable oils & -0.10 & 0.07 & -0.24 & 0.11 \\
\hline Tuber crops & 0.14 & 0.09 & 0.24 & -0.04 \\
\hline Fast food & 0.14 & -0.08 & -0.15 & 0.73 \\
\hline Ice cream & 0.07 & -0.09 & -0.16 & 0.60 \\
\hline Sweets & 0.17 & 0.07 & -0.16 & 0.49 \\
\hline Snacks & 0.16 & -0.21 & -0.16 & 0.47 \\
\hline Dairy products & 0.17 & -0.16 & -0.01 & 0.32 \\
\hline Red meat & -0.14 & 0.12 & 0.08 & -0.01 \\
\hline Eggs & 0.71 & 0.01 & 0.11 & 0.02 \\
\hline Proportion of explained variance (\%) & 8.57 & 8.49 & 8.23 & 7.21 \\
\hline
\end{tabular}

Moreover, the nutrient patterns and factor loading scores are presented in Table 4. Factor 1, with high loadings for isoleucine, valine, phenylalanine, leucine, histidine, threonine, lysine, tryptophan, carbohydrate, methionine, was labeled as the "amino acid-carbohydrate" nutrient pattern. Factor 2, with high loadings for folic acid, vitamin $\mathrm{B}_{6}$, dietary fiber, magnesium, iron, potassium, vitamin $\mathrm{A}$, vitamin E, thiamine, copper, niacin, choline and vitamin C, was labeled as the "vitamin-dietary fiber" nutrient pattern. Factor 3, with high loadings for zinc, protein, phosphorus, selenium, calcium and riboflavin, was labeled as the "mineral-protein" nutrient pattern. Factor 4, with high loadings for total fat, polyunsaturated fatty acids, saturated fatty acids, monounsaturated fatty acids and cholesterol, but low loadings for methionine, manganese, and copper, was labeled as the "fatty acid-cholesterol" nutrient pattern. Overall, the four nutrient patterns amounted to $65.72 \%$ of the variance in food intake. We analyzed the ORs (95\% CIs) of tertiles of nutrient patterns and ADHD (Table 5). The highest tertile of the mineral-protein nutrient pattern (T3 vs. T1: OR, $0.53 ; 95 \% \mathrm{CI}$ : $0.32-0.88$; $p$ trend $=0.014$ ) was negatively associated with the risk of ADHD after adjusting for other potential confounding factors. However, the amino acid-carbohydrate, vitamin-dietary fiber and fatty acid-cholesterol nutrient patterns were not significantly associated with the risk of ADHD. 
Table 3. Odds ratio (95\% CIs) of ADHD for tertiles of dietary patterns ${ }^{1}$.

\begin{tabular}{|c|c|c|c|c|}
\hline & \multicolumn{3}{|c|}{ Tertiles of Dietary Energy-Adjusted Intake } & \multirow{2}{*}{$p$ for Trend } \\
\hline & T1 (Referent) & T2 & T3 (Highest) & \\
\hline \multicolumn{5}{|c|}{ Factor 1 (vegetable-fruit dietary pattern) } \\
\hline$n$ (ADHD/control) & $108 / 90$ & $94 / 103$ & $94 / 103$ & \\
\hline Model 1 & 1.00 & $0.76(0.51,1.13)$ & $0.76(0.51,1.13)$ & 0.293 \\
\hline Model 2 & 1.00 & $0.72(0.43,1.19)$ & $0.69(0.42,1.13)$ & 0.274 \\
\hline \multicolumn{5}{|c|}{ Factor 2 (fish-white meat dietary pattern) } \\
\hline$n$ (ADHD/control) & $118 / 80$ & $90 / 107$ & $88 / 109$ & \\
\hline Model 1 & 1.00 & $0.57(0.38,0.85)$ & $0.55(0.37,0.82)$ & 0.003 \\
\hline Model 2 & 1.00 & $0.64(0.38,1.06)$ & $0.44(0.27,0.73)$ & 0.006 \\
\hline \multicolumn{5}{|c|}{ Factor 3 (grain-bean dietary pattern) } \\
\hline$n$ (ADHD/control) & $114 / 84$ & $92 / 105$ & $90 / 107$ & \\
\hline Model 1 & 1.00 & $0.65(0.43,0.96)$ & $0.62(0.42,0.92)$ & 0.018 \\
\hline Model 2 & 1.00 & $0.61(0.37,1.01)$ & $0.60(0.36,1.05)$ & 0.087 \\
\hline \multicolumn{5}{|c|}{ Factor 4 (fast food-sweet dietary pattern) } \\
\hline$n$ (ADHD/control) & $91 / 106$ & $95 / 102$ & $110 / 88$ & \\
\hline Model 1 & 1.00 & $1.09(0.73,1.61)$ & $1.46(0.98,2.16)$ & 0.148 \\
\hline Model 2 & 1.00 & $0.94(0.57,1.57)$ & $1.25(0.76,2.06)$ & 0.490 \\
\hline
\end{tabular}

Models 1 and 2: from conditional logistic model. Model 1: without further adjustment; Model 2: covariates adjusted for other potential confounding factors, including BMI, energy intake, family history of ADHD, household composition, maternal smoking during pregnancy, maternal drinking during pregnancy, paternal smoking before childbirth, paternal smoking after childbirth, maternal abortion history, maternal age at childbirth, parents' education, household income, labor or delivery complications, birth weight, twin, full-term pregnancy, breast feeding, emotional abuse, and family conflicts; ${ }^{1}$ : ORs ( $95 \% \mathrm{CI}$ ) for all such values.

Table 4. Factor loading matrix for the four identified nutrient patterns in the study children ${ }^{1}$.

\begin{tabular}{|c|c|c|c|c|}
\hline \multirow[b]{2}{*}{ Nutrient $^{2}$} & \multicolumn{4}{|c|}{ Nutrient Patterns } \\
\hline & $\begin{array}{c}\text { Factor } 1 \\
\text { (Amino Acid-Carbohydrate) }\end{array}$ & $\begin{array}{c}\text { Factor } 2 \\
\text { (Vitamin-Dietary Fiber) }\end{array}$ & $\begin{array}{c}\text { Factor } 3 \\
\text { (Mineral-Protein) }\end{array}$ & $\begin{array}{c}\text { Factor } 4 \\
\text { (Fatty Acid-Cholesterol) }\end{array}$ \\
\hline Isoleucine & 0.76 & 0.15 & 0.16 & 0.07 \\
\hline Valine & 0.76 & 0.14 & 0.20 & 0.05 \\
\hline Phenylalanine & 0.75 & 0.18 & 0.12 & 0.03 \\
\hline Leucine & 0.74 & 0.16 & 0.18 & 0.06 \\
\hline Histidine & 0.64 & 0.20 & 0.19 & 0.08 \\
\hline Threonine & 0.63 & 0.13 & 0.22 & 0.09 \\
\hline Lysine & 0.52 & 0.16 & 0.19 & 0.10 \\
\hline Tryptophan & 0.51 & 0.21 & 0.10 & -0.20 \\
\hline Carbohydrate & 0.50 & -0.10 & -0.22 & -0.20 \\
\hline Methionine & 0.34 & 0.13 & 0.24 & -0.47 \\
\hline Folic acid & 0.06 & 0.64 & 0.06 & 0.15 \\
\hline Vitamin $B_{6}$ & 0.23 & 0.62 & -0.08 & 0.09 \\
\hline Dietary fiber & 0.21 & 0.58 & 0.12 & -0.01 \\
\hline Magnesium & 0.16 & 0.51 & 0.23 & -0.15 \\
\hline Iron & 0.23 & 0.43 & 0.24 & -0.18 \\
\hline Potassium & 0.19 & 0.42 & 0.24 & -0.13 \\
\hline Vitamin A & -0.05 & 0.40 & 0.18 & 0.07 \\
\hline Vitamin E & 0.15 & 0.40 & 0.02 & 0.17 \\
\hline Thiamine & 0.19 & 0.34 & 0.20 & -0.07 \\
\hline Copper & 0.22 & 0.34 & 0.21 & -0.31 \\
\hline Niacin & 0.02 & 0.33 & 0.17 & -0.18 \\
\hline Choline & 0.21 & 0.32 & 0.04 & 0.16 \\
\hline Vitamin C & -0.04 & 0.32 & 0.06 & -0.14 \\
\hline Iodine & 0.16 & 0.20 & -0.06 & 0.17 \\
\hline Sodium & -0.08 & 0.09 & 0.09 & 0.08 \\
\hline Zinc & 0.19 & 0.23 & 0.59 & -0.17 \\
\hline Protein & 0.21 & 0.18 & 0.54 & -0.16 \\
\hline Phosphorus & 0.21 & 0.16 & 0.50 & 0.01 \\
\hline Selenium & 0.03 & 0.11 & 0.49 & -0.16 \\
\hline Riboflavin & 0.06 & 0.03 & 0.47 & 0.13 \\
\hline Calcium & 0.24 & 0.07 & 0.42 & 0.03 \\
\hline Total fat & -0.11 & -0.15 & 0.16 & 0.57 \\
\hline Polyunsaturated fatty acids & 0.16 & 0.08 & 0.18 & 0.53 \\
\hline Saturated fatty acids & 0.03 & -0.10 & -0.25 & 0.43 \\
\hline Monounsaturated fatty acids & 0.18 & 0.16 & 0.01 & 0.39 \\
\hline Cholesterol & 0.16 & -0.16 & 0.13 & 0.34 \\
\hline Manganese & 0.18 & 0.19 & 0.18 & -0.32 \\
\hline Proportion of explained variance (\%) & 24.99 & 16.93 & 12.90 & 10.38 \\
\hline
\end{tabular}

${ }^{1}$ : Dietary patterns were determined by factor analysis; ${ }^{2}$ : The factor-loading scores with absolute values of $\geqslant 0.30$ are bolded. 
Table 5. Odds ratio (95\% CIs) of ADHD for tertiles of nutrient patterns ${ }^{1}$.

\begin{tabular}{|c|c|c|c|c|}
\hline & \multicolumn{3}{|c|}{ Tertiles of Nutrient Energy-Adjusted Intake } & \multirow{2}{*}{$p$ for Trend } \\
\hline & T1 (Referent) & T2 & T3 (Highest) & \\
\hline \multicolumn{5}{|c|}{ Factor 1 (amino acid-carbohydrate nutrient pattern) } \\
\hline$n(\mathrm{ADHD} /$ control $)$ & $103 / 93$ & $104 / 94$ & $89 / 109$ & \\
\hline Model 1 & 1.00 & $0.99(0.67,1.48)$ & $0.74(0.50,1.10)$ & 0.220 \\
\hline Model 2 & 1.00 & $1.20(0.74,1.97)$ & $0.89(0.54,1.46)$ & 0.449 \\
\hline \multicolumn{5}{|c|}{ Factor 2 (vitamin-dietary fiber nutrient pattern) } \\
\hline$n(\mathrm{ADHD} /$ control $)$ & $105 / 92$ & $94 / 104$ & $97 / 100$ & \\
\hline Model 1 & 1.00 & $0.79(0.53,1.18)$ & $0.85(0.57,1.26)$ & 0.495 \\
\hline Model 2 & 1.00 & $0.87(0.53,1.41)$ & $0.95(0.58,1.55)$ & 0.842 \\
\hline \multicolumn{5}{|c|}{ Factor 3 (mineral-protein nutrient pattern) } \\
\hline$n(\mathrm{ADHD} /$ control $)$ & $113 / 85$ & $107 / 90$ & $76 / 121$ & \\
\hline Model 1 & 1.00 & $0.89(0.60,1.33)$ & $0.47(0.32,0.71)$ & $<0.001$ \\
\hline Model 2 & 1.00 & $0.79(0.49,1.28)$ & $0.53(0.32,0.88)$ & 0.014 \\
\hline \multicolumn{5}{|c|}{ Factor 4 (fatty acid-cholesterol nutrient pattern) } \\
\hline$n(\mathrm{ADHD} /$ control $)$ & $93 / 104$ & $101 / 96$ & $102 / 96$ & \\
\hline Model 1 & 1.00 & $1.18(0.79,1.75)$ & $1.19(0.80,1.76)$ & 0.631 \\
\hline Model 3 & 1.00 & $1.50(0.92,2.46)$ & $1.50(0.91,2.47)$ & 0.181 \\
\hline
\end{tabular}

Models 1 and 2: from conditional logistic model. Model 1: without further adjustment; Model 2: covariates adjusted for other potential confounding factors, including BMI, energy intake, family history of ADHD, household composition, maternal smoking during pregnancy, maternal drinking during pregnancy, paternal smoking before childbirth, paternal smoking after childbirth, maternal abortion history, maternal age at childbirth, parents' education, household income, labor or delivery complications, birth weight, twin, full-term pregnancy, breast feeding, emotional abuse, and family conflicts; ${ }^{1}$ : ORs ( $95 \% \mathrm{CI}$ ) for all such values.

The associations between blood element (iron, zinc, calcium, copper and magnesium) levels and ADHD were conducted using conditional logistic regression. The concentration of blood zinc was significantly inversely associated with the risk of ADHD, as shown in model 1 of Table $6(p=0.005 ; 95 \%$ CI for OR was 0.96-0.99). After an adjustment was made in model 2 for other potential confounding factors, inversely significant associations existed between the risk of ADHD and blood zinc in Table 6 $(p=0.008 ; 95 \%$ CI for OR was $0.96-0.99)$. In the fully adjusted model, one SD increase of blood zinc concentration was associated with an OR of 0.73 (95\% CI 0.60-0.89) for ADHD. However, no relation was observed between blood iron, calcium, copper, or magnesium concentration and $\operatorname{ADHD}(p>0.05)$.

Table 6. Odds ratio (95\% CIs) of ADHD for blood elements.

\begin{tabular}{|c|c|c|c|c|c|c|c|c|}
\hline \multirow[b]{2}{*}{ Blood Elements } & \multicolumn{4}{|c|}{ Model 1} & \multicolumn{4}{|c|}{ Model 2} \\
\hline & $\begin{array}{c}\text { OR }^{1} \\
(95 \% \mathrm{CI})\end{array}$ & $p$ & $\begin{array}{c}\text { OR per SD } \\
(95 \% \mathrm{CI})\end{array}$ & $p$ & $\begin{array}{c}\text { OR } \\
(95 \% \text { CI })\end{array}$ & $p$ & $\begin{array}{c}\text { OR per SD } \\
(95 \% \mathrm{CI})\end{array}$ & $p$ \\
\hline Zinc $(\mu \mathrm{mol} / \mathrm{L})$ & $\begin{array}{c}0.96 \\
(0.96-0.99)\end{array}$ & 0.005 & $\begin{array}{c}0.74 \\
(0.60-0.90)\end{array}$ & 0.002 & $\begin{array}{c}0.98 \\
(0.96-0.99)\end{array}$ & 0.008 & $\begin{array}{c}0.73 \\
(0.60-0.89)\end{array}$ & 0.003 \\
\hline Iron $(\mathrm{mmol} / \mathrm{L})$ & $\begin{array}{c}1.16 \\
(0.90-1.49)\end{array}$ & 0.243 & $\begin{array}{c}1.22 \\
(0.99-1.49)\end{array}$ & 0.073 & $\begin{array}{c}1.11 \\
(0.83-1.47)\end{array}$ & 0.492 & $\begin{array}{c}1.19 \\
(0.98-1.46)\end{array}$ & 0.086 \\
\hline Calcium (mmol/L) & $\begin{array}{c}0.77 \\
(0.49-1.21)\end{array}$ & 0.258 & $\begin{array}{c}0.96 \\
(0.80-1.14) \\
\end{array}$ & 0.608 & $\begin{array}{c}0.82 \\
(0.18-3.68)\end{array}$ & 0.795 & $\begin{array}{c}0.94 \\
(0.78-1.12)\end{array}$ & 0.464 \\
\hline Copper $(\mu \mathrm{mol} / \mathrm{L})$ & $\begin{array}{c}1.02 \\
(0.96-1.08)\end{array}$ & 0.531 & $\begin{array}{c}1.09 \\
(0.89-1.33)\end{array}$ & 0.399 & $\begin{array}{c}1.03 \\
(0.96-1.10)\end{array}$ & 0.407 & $\begin{array}{c}1.09 \\
(0.89-1.33)\end{array}$ & 0.424 \\
\hline Magnesium (mmol/L) & $\begin{array}{c}0.78 \\
(0.47-1.28)\end{array}$ & 0.320 & $\begin{array}{c}0.98 \\
(0.83-1.15)\end{array}$ & 0.763 & $\begin{array}{c}0.74 \\
(0.42-1.29)\end{array}$ & 0.286 & $\begin{array}{c}0.98 \\
(0.83-1.15)\end{array}$ & 0.804 \\
\hline
\end{tabular}

Models 1 and 2: from conditional logistic model. Model 1: unadjusted; Model 2: covariates adjusted for other potential confounding factors, including BMI, energy intake, family history of ADHD, household composition, maternal smoking during pregnancy, maternal drinking during pregnancy, paternal smoking before childbirth, paternal smoking after childbirth, maternal abortion history, maternal age at childbirth, parents' education, household income, labor or delivery complications, birth weight, twin, full-term pregnancy, breast feeding, emotional abuse, and family conflicts; ${ }^{1}$ : OR indicates likelihood of an ADHD. 


\section{Discussion}

In the present case-control study, we identified four major dietary patterns and four major nutrient patterns for Chinese children. A fish-white meat dietary pattern rich in shellfish, deep water fish, white meat, freshwater fish, fungi and algae and organ meat was inversely associated with ADHD. Further analysis found that a mineral-protein nutrient pattern rich in zinc, protein, phosphorus, selenium, calcium and riboflavin was inversely associated with ADHD. Additionally, the blood zinc was also negatively related to ADHD. To the best of our knowledge, this study, with 296 pairs of age- and gender-matched Chinese children with ADHD and controls, is the first to specifically identify the potential influence of nutrient patterns on the risk of ADHD based on the association between dietary patterns and ADHD.

The diet pattern (including dietary pattern and nutrient pattern) is an aggregate variable that is derived from special statistical methods, which summarizes the food and nutrient intake to create a meaningful overall representation of a large and complex set of interrelated diet factors. Recently, diet pattern analysis has emerged in the field of nutritional epidemiology as an alternative and complementary approach for examining the relationship between diet and the risk of chronic diseases. Rather than considering individual foods or nutrients, diet patterns conceptually represent a broader picture of food and nutrient consumption and may thus be more predictive of disease risk than individual foods or nutrients [34]. Moreover, a healthy diet pattern may be an effective and practical method to prevent or control ADHD.

To date, three previous studies have examined the associations between dietary patterns and ADHD [18-20]. These studies and our current research all suggested that several special dietary patterns were associated with ADHD. It is interesting that the healthy dietary patterns, which were significant, protectively related to ADHD in the case-control studies of Woo et al. and ours, included vegetable, fresh fruit, fish, white meat, and whole grains [20], whereas the unhealthy dietary patterns that were significant, adversely related to ADHD in the cross-sectional studies of Howard et al. and Azadbakht et al., included fast food, ice cream, sweets, snacks, and red meat $[18,19]$.

To further explore the relationship of dietary patterns and ADHD, a nutrient pattern analysis was conducted in our study. In addition, a mineral-protein nutrient pattern typified by the consumption of zinc, protein, phosphorus, selenium, riboflavin and calcium was associated with a $53 \%(95 \%$ CI, 29\%-68\%) decrease in the risk of ADHD (T3 vs. T1). This finding interestingly supported the relationship of fish-white meat pattern and ADHD, because the fish and white meat were abundant with zinc, selenium, calcium, phosphorus and purified protein [24,25]. The results of Howard et al. and Azadbakht et al. also supported our finding on the opposite side [18,19]. Their unhealthy dietary patterns such as fast food consumption were found to be associated with having a lower intake of mineral nutrients, including zinc, calcium and phosphorus [35,36]. However, it was not found in our study that the PUFAs abundantly contained in fish were associated with ADHD [14,37], which was reported by some studies. In our nutrient factor analysis, saturated fatty acids and polyunsaturated fatty acids were always loaded together in the fatty acid-cholesterol nutrient pattern. We regarded that the association between dietary patterns and ADHD might be mainly attributed to the minerals in the mineral-protein nutrient pattern.

To further verify and elucidate the relation between minerals and ADHD in our study, the essential elements zinc, iron, calcium, copper and magnesium that were closely related to children's growth and development were detected in children's blood [38]. The results showed that blood zinc was inversely associated with ADHD and a lower zinc level was discovered in the ADHD children. These findings corresponded with the above nutrient pattern results. The same results were also discovered in the studies conducted by Akhondzadeh et al. [39] and Bilici et al. [15], which also found that children with ADHD are associated with zinc deficiency, and zinc supplementation can reduce ADHD symptoms in children with low zinc levels. It is known that zinc is necessary for many metal-enzyme complexes, lots of them located in the nervous system [40], and that it contributes to construction and function of the brain [41]. Zinc is also essential for conversion of dietary pyridoxine to its active form, pyridoxal 
phosphate, and pyridoxine is necessary for conversion of tryptophan to serotonin, which had a close relationship with ADHD [15,42]. In addition, zinc is basic for the production and modulation of melatonin, which helps regulate dopamine function, and is supposed to be an important factor in ADHD $[43,44]$. Therefore, zinc played a major role in the relationships between minerals and ADHD in our study, and the blood zinc was helpful for distinguishing ADHD in children.

Some points need to be considered in the interpretation of our findings. First, many well-known lifestyle factors and other risk factors for ADHD were significantly different between the subjects with ADHD and the controls (e.g., family history of ADHD, emotional abuse, full-term pregnancy, household composition, maternal education, and maternal abortion history). Although we adjusted for many such factors using statistical analysis, residual confounding was still unavoidable because of measurement errors and missing adjustments for several unmeasured factors. Second, the FFQs are known to contain a certain degree of measurement error although the FFQ used in our study has been previously validated. Third, the four major dietary patterns derived from our data explained only $32.5 \%$ of total variance, suggesting the existence of other dietary patterns. However, these values should be interpreted with caution because they depend heavily on the total number of variables used in the factor analysis [31]. Finally, the studies with hospital-based controls are prone to selection bias, which might confound the results.

\section{Conclusions}

In conclusion, our findings suggest that the consumption of a fish-white meat dietary pattern and a mineral-protein nutrient pattern may have beneficial effects on ADHD, and may be effective and practical methods to prevent or control ADHD in Chinese children. Additionally, blood zinc might be helpful to distinguish ADHD in Chinese children. Further prospective studies are required to confirm these findings.

Acknowledgments: This work was supported by the National Nature Science Foundation of China (No. 81273120, 21267017, 30760211, 30960324), the Jiangxi Provincial Natural Science Foundation (No. 20132BAB205069), and the Nanchang University Innovation Fund of Postgraduates (No. cx2015106).

Author Contributions: G.Q.F. conceived and developed the overall research plan, and had primary responsibility for final content. G.Q.F. and S.P.Z. designed the research; F.K.Z. and G.Q.F. analyzed the data and wrote the paper; F.K.Z., F.Y.W., Y.C. and C.F. conducted the research. All authors read and approved the final manuscript.

Conflicts of Interest: The authors declare no conflict of interest.

\section{Abbreviations}

The following abbreviations are used in this manuscript:

$\begin{array}{ll}\text { ADHD } & \text { attention deficit hyperactivity disorder } \\ \text { BMI } & \text { body mass index } \\ \text { CIs } & \text { confidence intervals } \\ \text { FFQ } & \text { food frequency questionnaire } \\ \text { ORs } & \text { odds ratios } \\ \text { PUFAs } & \begin{array}{l}\text { polyunsaturated fatty acids } \\ \text { SD }\end{array} \\ \text { standard deviation } \\ \text { 24 } 4 \text { h diet recalls }\end{array}$

\section{Appendix}

Table A1. Food groupings used in the dietary pattern analyses.

\begin{tabular}{cl}
\hline Food or Food Groups & \multicolumn{1}{c}{ Food Items } \\
\hline Grains & rice, millet, yellow rice, corn \\
\hline Processed grains & bread, noodle, rice noodle, steamed roll \\
\hline Red meat & pork, pig trotters, beef, beef brisket, mutton, and other meat \\
\hline White meat & chicken, chicken paw, duck, duck feet, goose, and other poultry \\
\hline
\end{tabular}


Table A1. Cont.

\begin{tabular}{|c|c|}
\hline Food or Food Groups & Food Items \\
\hline Organ meat & pork, beef and mutton liver; chicken and duck giblets \\
\hline Dairy products & cheese, margarine, yoghurt, skim and powder milk \\
\hline Deep water fish & ribbonfish, yellow croaker, cuttlefish, snailfish \\
\hline Freshwater fish & crucian carp, yellow catfish, silver carp, grass carp, rice field eel \\
\hline Shellfish & shrimp, crab, shellfish \\
\hline Fruits & banana, papaya, water melon, apple, honeydew, mango, pineapple, jackfruit, guava, orange \\
\hline Tuber crops & sweet potato, dry sweet potato, cassava \\
\hline Soya beans & soya bean, soya-bean milk, soya-bean flour, tofu, bean curd \\
\hline Other beans & mung bean, red bean, broad bean, and other kidney beans \\
\hline Root vegetables & carrot, white radish, turnip \\
\hline Fruiting vegetables & $\begin{array}{l}\text { pepper, eggplant, cucumbers, tomato, white gourd, pumpkin, cucumber, sponge gourd, bitter } \\
\text { melon, courgettes }\end{array}$ \\
\hline Leafy vegetables & cabbage, broccoli, greens, cauliflower, celery, water spinach, lettuces, spinach, chive, leek \\
\hline Tuber vegetables & asparagus lettuce, bamboo shoots, water chestnut, lotus root, yams, taro, ginger, garlic, onion \\
\hline Fungi and algae & mushroom family, seaweed \\
\hline Snacks & potato chips, bread, cake, biscuits, other starchy snacks, pork floss \\
\hline Fast food & convenience foods, frozen foods \\
\hline Ice cream & ice cream \\
\hline Drinks & $\begin{array}{l}\text { cola, sprite, juices and juice drinks, vegetable juice drinks, milk drinks, chocolate soy milk, } \\
\text { almond milk, tea beverage }\end{array}$ \\
\hline Animal fats & lard \\
\hline Vegetable oils & mixed oil, peanut oil, tea oil, olive oil, soybean oil, other edible oil \\
\hline Condiments & $\begin{array}{l}\text { soy sauce, vinegar, broad bean butter, pepper sauce, preserved bean curd, pickles, pepper, wild } \\
\text { pepper, chili powder, salt, monosodium glutamate, others }\end{array}$ \\
\hline Eggs & egg, duck's egg, preserved egg, other eggs \\
\hline Nuts & walnut, cedar nut, hazelnut, peanut, seeds of sunflower, watermelon and pumpkin \\
\hline Sweets & candy, chocolate, preserved fruits, candied Chinese date \\
\hline
\end{tabular}

\section{References}

1. American Psychiatric Association. Diagnostic E Statistical Manual for Mental Disorders, 4th ed.; Text Revision (DSM-IV-R): Washington, DC, USA, 2000.

2. Biederman, J.; Faraone, S.V. Attention-deficit hyperactivity disorder. Lancet 2005, 366, 237-248. [CrossRef]

3. Satterfield, J.H.; Faller, K.J.; Crinella, F.M.; Schell, A.M.; Swanson, J.M.; Homer, L.D. A 30-year prospective follow-up study of hyperactive boys with conduct problems: Adult criminality. J. Am. Acad. Child Adolesc. Psychiatry 2007, 46, 601-610. [CrossRef] [PubMed]

4. Pliszka, S.R. The neuropsychopharmacology of attentiondeficit/hyperactivity disorder. Biol. Psychiatry 2005, 57, 1385-1390. [CrossRef] [PubMed]

5. Simonoff, E.; Taylor, E.; Baird, G.; Bernard, S.; Chadwick, O.; Liang, H.; Whitwell, S.; Riemer, K.; Sharma, K.; Sharma, S.P.; et al. Randomized controlled double-blind trial of optimal dose methylphenidate in children and adolescents with severe attention deficit hyperactivity disorder and intellectual disability. J. Child Psychol. Psychiatry 2013, 54, 527-535. [CrossRef] [PubMed]

6. Sharma, A.; Couture, J. A review of the pathophysiology, etiology, and treatment of attention-deficit hyperactivity disorder (ADHD). Ann. Pharmacother. 2014, 48, 209-225. [CrossRef] [PubMed]

7. Greenhill, L.L.; Muniz, R.; Ball, R.R.; Levine, A.; Pestreich, L.; Jiang, H. Efficacy and safety of dexmethylphenidate extended-release capsules in children with attention-deficit/hyperactivity disorder. J. Am. Acad. Child Adolesc. Psychiatry 2006, 45, 817-823. [CrossRef] [PubMed] 
8. Findling, R.L.; Turnbow, J.; Burnside, J.; Melmed, R.; Civil, R.; Li, Y. A randomized, double-blind, multicenter, parallel-group, placebo-controlled, dose-optimization study of the methylphenidate transdermal system for the treatment of ADHD in adolescents. CNS Spectr. 2010, 15, 419-430. [PubMed]

9. Millichap, J.G. Etiologic classification of attention-deficit/hyperactivity disorder. Pediatrics 2008, 121, e358-e365. [CrossRef] [PubMed]

10. Millichap, J.G.; Yee, M.M. The diet factor in attention-deficit/hyperactivity disorder. Pediatrics 2012, 129, 330-337. [CrossRef] [PubMed]

11. Kruesi, M.J.; Rapoport, J.L.; Cummings, E.M.; Berg, C.J.; Ismond, D.R.; Flament, M.; Yarrow, M.; Zahn-Waxler, C. Effects of sugar and aspartame on aggression and activity in children. Am. J. Psychiatry 1987, 144, 1487-1490. [PubMed]

12. Stevenson, J.; Sonuga-Barke, E.; McCann, D.; Grimshaw, K.; Parker, K.M.; Rose-Zerilli, M.J.; Holloway, J.W.; Warner, J.O. The role of histamine degradation gene polymorphisms in moderating the effects of food additives on children's ADHD symptoms. Am. J. Psychiatry 2010, 167, 1108-1115. [CrossRef] [PubMed]

13. Pelsser, L.M.; Frankena, K.; Toorman, J.; Savelkoul, H.F.; Dubois, A.E.; Pereira, R.R.; Haagen, T.A.; Rommelse, N.N.; Buitelaar, J.K. Effects of a restricted elimination diet on the behaviour of children with attention-deficit hyperactivity disorder (INCA study): A randomised controlled trial. Lancet 2011, 377, 494-503. [CrossRef]

14. Ng, K.H.; Meyer, B.J.; Reece, L.; Sinn, N. Dietary PUFA intakes in children with attention-deficit/hyperactivity disorder symptoms. Br. J. Nutr. 2009, 102, 1635-1641. [CrossRef] [PubMed]

15. Bilici, M.; Yildirim, F.; Kandil, S.; Bekaroğlu, M.; Yildirmiş, S.; Değer, O.; Ulgen, M.; Yildiran, A.; Aksu, H. Double-blind, placebo-controlled study of zinc sulfate in the treatment of attention deficit hyperactivity disorder. Prog. Neuropsychopharmacol. Biol. Psychiatry 2004, 28, 181-190. [CrossRef] [PubMed]

16. Konofal, E.; Lecendreux, M.; Deron, J.; Marchand, M.; Cortese, S.; Zaïm, M.; Mouren, M.C.; Arnulf, I. Effects of iron supplementation on attention deficit hyperactivity disorder in children. Pediatr. Neurol. 2008, 38, 20-26. [CrossRef] [PubMed]

17. Jacobs, D.R., Jr.; Steffen, L.M. Nutrients, foods, and dietary patterns as exposures in research: A framework for food synergy. Am. J. Clin. Nutr. 2003, 78, 508S-513S. [PubMed]

18. Howard, A.L.; Robinson, M.; Smith, G.J.; Ambrosini, G.L.; Piek, J.P.; Oddy, W.H. ADHD is associated with a “Western" dietary pattern in adolescents. J. Atten. Disord. 2011, 15, 403-411. [CrossRef] [PubMed]

19. Azadbakht, L.; Esmaillzadeh, A. Dietary patterns and attention deficit hyperactivity disorder among Iranian children. Nutrition 2012, 28, 242-249. [CrossRef] [PubMed]

20. Woo, H.D.; Kim, D.W.; Hong, Y.S.; Kim, Y.M.; Seo, J.H.; Choe, B.M.; Park, J.H.; Kang, J.W.; Yoo, J.H.; Chueh, H.W.; et al. Dietary patterns in children with attention deficit/hyperactivity disorder (ADHD). Nutrients 2014, 6, 1539-1553. [CrossRef] [PubMed]

21. Shahar, D.; Shai, I.; Vardi, H.; Brener-Azrad, A.; Fraser, D. Development of a semi-quantitative Food Frequency Questionnaire (FFQ) to assess dietary intake of multiethnic populations. Eur. J. Epidemiol. 2003, 18, 855-861. [CrossRef] [PubMed]

22. World Health Organization. Obesity: Preventing and managing the global epidemic. Report of a WHO consultation. World Health Organ. Tech. Rep. Ser. 2000, 894, 1-253.

23. Willett, W.C. Food-frequency methods. In Nutritional Epidemiology, 2nd ed.; Oxford University Press: New York, NY, USA, 1998; pp. 74-100.

24. Yang, Y.X.; Wang, G.Y.; Pan, X.C. China Food Composition 2002; Peking University Medical Press: Beijing, China, 2002.

25. Yang, Y.X. China Food Composition 2004; Peking University Medical Press: Beijing, China, 2005.

26. Biederman, J.; Faraone, S.V. The Massachusetts General Hospital studies of gender influences on attention-deficit/hyperactivity disorderin youth and relatives. Psychiatr. Clin. N. Am. 2004, 27, 225-232. [CrossRef] [PubMed]

27. Arnett, A.B.; Pennington, B.F.; Willcutt, E.G.; DeFries, J.C.; Olson, R.K. Sex differences in ADHD symptom severity. J. Child Psychol. Psychiatry 2015, 56, 632-639. [CrossRef] [PubMed]

28. Swanson, J.M.; Kinsbourne, M.; Nigg, J.; Lanphear, B.; Stefanatos, G.A.; Volkow, N.; Taylor, E.; Casey, B.J.; Castellanos, F.X.; Wadhwa, P.D. Etiologic subtypes of attention-deficit/hyperactivity disorder: Brain imaging, molecular genetic and environmental factors and the dopamine hypothesis. Neuropsychol. Rev. 2007, 17, 39-59. [CrossRef] [PubMed] 
29. Pettersson, E.; Sjölander, A.; Almqvist, C.; Anckarsäter, H.; D’Onofrio, B.M.; Lichtenstein, P.; Larsson, H. Birth weight as an independent predictor of ADHD symptoms: A within-twin pair analysis. J. Child Psychol. Psychiatry 2015, 56, 453-459. [CrossRef] [PubMed]

30. Kleinbaum, D.G.; Kupper, L.L.; Muller, K.E. Variable reduction and factor analysis. In Applied Regression Analysis and Other Multivariable Methods; PWS Kent Publishing Company: Boston, MA, USA, 1988; pp. 595-640.

31. Kim, J.-O.; Mueller, C.W. Factor Analysis: Statistical Methods and Practical Issues; Sage Publications Inc.: Thousand Oaks, CA, USA, 1978.

32. Northstone, K.; Ness, A.R.; Emmett, P.M.; Rogers, I.S. Adjusting for energy intake in dietary pattern investigations using principal components analysis. Eur. J. Clin. Nutr. 2008, 62, 931-938. [CrossRef] [PubMed]

33. Willett, W.C. Implications of total energy intake for epidemiologic analysis. In Nutritional Epidemiology, 2nd ed.; Oxford University Press: New York, NY, USA, 1998; pp. 273-301.

34. Hu, F.B. Dietary pattern analysis: A new direction in nutritional epidemiology. Curr. Opin. Lipidol. 2002, 13, 3-9. [CrossRef] [PubMed]

35. Bowman, S.A.; Vinyard, B.T. Fast food consumption of U.S. adults: Impact on energy and nutrient intakes and overweight status. J. Am. Coll. Nutr. 2004, 23, 163-168. [CrossRef] [PubMed]

36. El-Seweidy, M.M.; Hashem, R.M.; Abo-El-matty, D.M.; Mohamed, R.H. Frequent inadequate supply of micronutrients in fast food induces oxidative stress and inflammation in testicular tissues of weanling rats. J. Pharm. Pharmacol. 2008, 60, 1237-1242. [CrossRef] [PubMed]

37. Johnson, M.; Ostlund, S.; Fransson, G.; Kadesjö, B.; Gillberg, C. Omega-3/omega-6 fatty acids for attention deficit hyperactivity disorder: A randomized placebo-controlled trial in children and adolescents. J. Atten. Disord. 2009, 12, 394-401. [CrossRef] [PubMed]

38. Bourre, J.M. Effects of nutrients (in food) on the structure and function of the nervous system: Update on dietary requirements for brain. Part 1: Micronutrients. J. Nutr. Health Aging 2006, 10, 377-385. [PubMed]

39. Akhondzadeh, S.; Mohammadi, M.R.; Khademi, M. Zinc sulfate as an adjunct to methylphenidate for the treatment of attention deficit hyperactivity disorder in children: A double blind and randomized trial. BMC Psychiatry 2004, 4, 9. [CrossRef] [PubMed]

40. Toren, P.; Eldar, S.; Sela, B.A.; Wolmer, L.; Weitz, R.; Inbar, D.; Koren, S.; Reiss, A.; Weizman, R.; Laor, N. Zinc deficiency in attention-deficit hyperactivity disorder. Biol. Psychiatry 1996, 40, 1308-1310. [CrossRef]

41. Black, M.M. Zinc deficiency and child development. Am. J. Clin. Nutr. 1998, 68, 464S-469S. [PubMed]

42. Quist, J.R.; Kennedy, J.L. Genetics of childhood disorders: XXIII. ADHD, Part 7: The serotonin system. J. Am. Acad. Child Adolesc. Psychiatry 2001, 40, 253-256. [CrossRef] [PubMed]

43. Kirby, K.; Floriani, V.; Bernstein, H. Diagnosis and management of attention-deficit hyperactivity disorder in children. Curr. Opin. Pediatr. 2001, 13, 190-199. [CrossRef] [PubMed]

44. Arnold, L.E.; DiSilvestro, R.A. Zinc in attention-deficit/hyperactivity disorder. J. Child Adolesc. Psychopharmacol. 2005, 15, 619-627. [CrossRef] [PubMed]

(c) 2016 by the authors; licensee MDPI, Basel, Switzerland. This article is an open access article distributed under the terms and conditions of the Creative Commons Attribution (CC-BY) license (http://creativecommons.org/licenses/by/4.0/). 